\title{
Molecular characterization of Wolbachia infection in bed bugs (Cimex lectularius) collected from several localities in France
}

\author{
Mohammad Akhoundi ${ }^{1, *}$, Arnaud Cannet ${ }^{2}$, Céline Loubatier ${ }^{3}$, Jean-Michel Berenger ${ }^{4}$, Arezki Izri ${ }^{4,5}$, \\ Pierre Marty ${ }^{1,2}$, and Pascal Delaunay ${ }^{1,2}$ \\ 1 Service de Parasitologie-Mycologie, Hôpital de l'Archet, Centre Hospitalier Universitaire de Nice, 06000 Nice, France \\ 2 Inserm U1065, Centre Méditerranéen de Médecine Moléculaire, Faculté de Médecine, Université Nice-Sophia Antipolis, \\ 06000 Nice, France \\ 3 Faculté de Médecine, Université Nice-Sophia Antipolis, 06000 Nice, France \\ 4 URMITE, UM63, CNRS 7278, IRD 198, Inserm 1095, Faculté de Médecine, Université Aix-Marseille, 13000 Marseille, France \\ 5 Service de Parasitologie-Mycologie, Hôpital Avicenne, Assistance Publique-Hôpitaux de Paris, 93000 Bobigny, France
}

Received 28 February 2016, Accepted 23 July 2016, Published online 5 August 2016

\begin{abstract}
Wolbachia symbionts are maternally inherited intracellular bacteria that have been detected in numerous insects including bed bugs. The objective of this study, the first epidemiological study in Europe, was to screen Wolbachia infection among Cimex lectularius collected in the field, using PCR targeting the surface protein gene (wsp), and to compare obtained Wolbachia strains with those reported from laboratory colonies of C. lectularius as well as other Wolbachia groups. For this purpose, 284 bed bug specimens were caught and studied from eight different regions of France including the suburbs of Paris, Bouches-du-Rhône, Lot-et-Garonne, and five localities in Alpes-Maritimes. Among the samples, 166 were adults and the remaining 118 were considered nymphs. In all, 47 out of 118 nymphs $(40 \%)$ and 61 out of 166 adults $(37 \%)$ were found positive on wsp screening. Among the positive cases, 10 samples were selected randomly for sequencing. The sequences had $100 \%$ homology with wsp sequences belonging to the F-supergroup strains of Wolbachia. Therefore, we confirm the similarity of Wolbachia strains detected in this epidemiological study to Wolbachia spp. reported from laboratory colonies of C. lectularius.
\end{abstract}

Key words: Bed bugs, Cimex lectularius, Symbiont, Wolbachia.

Résumé - Caractérisation moléculaire de l'infection par Wolbachia chez les punaises de lit (Cimex lectularius) recueillies dans plusieurs localités en France. Les symbiotes Wolbachia sont des bactéries intracellulaires maternellement héritées qui ont été détectés chez de nombreux insectes, y compris les punaises de lit. Les objectifs de cette étude, la première étude épidémiologique en Europe, était de cribler l'infection par Wolbachia chez les Cimex lectularius recueillis sur le terrain, en utilisant la PCR ciblant le gène de la protéine de surface (wsp) et de comparer la souche de Wolbachia obtenue avec celles rapportées des colonies de laboratoire de C. lectularius et d'autres groupes de Wolbachia. Dans ce but, 284 spécimens de punaises de lit ont été capturés et étudiés, provenant de huit régions différentes de la France, y compris les banlieues de Paris, les Bouchesdu-Rhône, le Lot-et-Garonne et cinq localités dans les Alpes-Maritimes. Parmi les échantillons, 166 étaient des adultes et le reste (118) ont été considérés comme des nymphes. Quarante-sept des 118 nymphes (40\%) et 61 des 166 adultes $(37 \%)$ ont été trouvés positifs pour le dépistage de wsp. Parmi les cas positifs, 10 échantillons ont été choisis au hasard pour le séquençage. Les séquences avaient $100 \%$ d'homologie avec des séquences de $w s p$ appartenant aux souches du supergroupe F de Wolbachia. Par conséquent, nous confirmons la similitude des souches de Wolbachia détectées dans cette étude épidémiologique à celles des Wolbachia spp. signalées dans les colonies de laboratoire de C. lectularius.

\section{Introduction}

Bed bugs are blood-sucking insects and human ectoparasites, and have re-emerged over the last two decades

*Corresponding author: m.akhoundi@yahoo.com worldwide. In economically advanced countries, they are a serious public health issue that still threaten many people. They may cause problems in housing facilities, public facilities, and residential complexes. They are therefore an important risk factor that cannot be neglected by the tourism industry, the housing industry, and public institutions. 
Bed bug infestations have been reported to have physical and psychological effects in humans. Despite isolation of several pathogens, found in the bed bug body, they have not been confirmed as a vector of pathogens to humans [18]. Recently, Salazar et al. [32] and Leulmi et al. [15] reported the vectorial competence of $C$. lectularius for Trypanosoma cruzi and Bartonella quintana transmissions in laboratory experiments. In addition, bed bug infections by Burkholderia multivorans have been reported by Saenz et al. [28], who screened different bed bug populations in the United States.

A wide range of symbiotic microorganisms are associated with insect hosts that mainly reside in their guts, body cavities, or cells $[4,13,19]$. Some obligate symbionts with a mutualistic nature - like Buchnera in aphids and Wigglesworthia in tsetse - have been reported to contribute to host fitness [9, 22], whereas some other symbionts such as Wolbachia are often parasitic causing negative effects in their hosts [24]. The latter seem to be obligate commensal symbionts and facultative parasites that are of importance due to their roles in forces driving the evolutionary transition into mutualism $[8,10]$.

Wolbachia are maternally inherited rickettsia-like bacteria (Gram-negative alpha-proteobacteria), harbored by a wide range of arthropods and are mainly found in the host gonads $[5,23,26,35]$. These intracellular bacteria were first reported in 1924 in the reproductive tissues of Culex pipientis mosquitos [11]. Since this discovery, several papers have reported the presence of these bacteria in the host tissues of many different arthropod species including bed bugs. This presence and association of Wolbachia in hosts is mainly considered as a commensal or somewhat parasitic relationship. The Wolbachia infection often leads to host reproductive phenotypes, such as cytoplasmic incompatibility, feminization, male-killing, anti-virus properties, parthenogenesis, increased or decreased fitness, and sperm-egg incompatibility, which consequently results in unfertilized eggs [6, 8, 16, 20, 34, 37]. In addition to the roles mentioned, Wolbachia have been shown to occupy bacteriocytes (specialized cells that constitute a pair of organs known as bacteriomes) and to be essential for bedbug growth and reproduction via provisioning of $\mathrm{B}$ vitamins $[14,21]$. Moreover, Wolbachia increase male bed bug fitness by increasing the egg laying rate of the female after mating. The bacterium also leads to an increase in female host fitness by increasing egg hatch and development success, increasing offspring body size, and reducing fitness costs (wounding and infection) associated with traumatic insemination [13].

Several Wolbachia strains have been reported from different arthropod species. They have been classified in eight major supergroups from A to $\mathrm{H}$. Wolbachia species belonging to A, B, and E groups infect diverse arthropods; C and D infect nematodes; $\mathrm{G}$ infects spiders and $\mathrm{H}$ infects termites, whereas $\mathrm{F}$ infects arthropods and nematodes $[3,21,25,27$, 29-31, 34]. Infections with Wolbachia species of F supergroup seem to be prevalent in the Cimicinae subfamily (Cimex and Oeciacus genera). The species appears to be monophyletic, suggesting that Wolbachia symbionts were first introduced to a primitive insect population and then diverged dependently, along with the insect hosts in this subfamily.

Despite this knowledge on the spread of Wolbachia infection among different arthropod hosts including bed bugs, the contribution rate of Wolbachia in field collected bed bug populations has not been studied sufficiently in Europe.

Therefore, the aim of the present study was to screen the prevalence of Wolbachia sp. that colonize naturally field collected populations of Cimex lectularius using a PCR-based survey, and to compare obtained Wolbachia strains with those that have been reported from laboratory colonized C. lectularius as well as other Wolbachia groups.

\section{Materials and methods}

Cimex lectularius specimens were collected from four different parts of France, including hotel and individual apartments from 2010 to 2012. They were caught from the suburbs of Paris (Saint-Ouen), Bouches-du-Rhône (Aix-en-Provence), Lot-et-Garonne (Agen), and AlpesMaritimes (Nice, Cannes, Le Cannet, Beausoleil, and La Roquette-sur-Siagne) (Fig. 1). All samples within infested structures were collected from a single room. All bed bugs (except the egg stage) were hand-removed by entomological tweezers during inspections, transferred immediately into the labeled microtubes containing ethanol $96 \%$, and stored at $-20{ }^{\circ} \mathrm{C}$ for further molecular analysis.

DNA was extracted using Qiagen's DNeasy extraction kit (Valencia, CA, USA) according to the manufacturer's protocol. Moreover, the purity and concentration of extracted DNA was measured using a NanoDrop spectrophotometer (BioTek Synergy 2, USA). The samples were then screened for the presence of Wolbachia species. For this purpose, specific primers for $w s p, 81 \mathrm{~F}$ (F: 5'-TGG TCC AAT AAG TGA TGA AGA AAC-3') and wsp 691R (R: 5'-AAA AAT TAA ACG CTA CTC CA-3'), were used for 600 bp fragment amplification of Wolbachia surface protein (wsp) by polymerase chain reaction [36]. A pair of positive (Wolbachia positive samples previously sequenced for confirmation) and negative (DNA free distilled water) controls were used in each PCR run. Following amplification, the samples were fractionated via horizontal submerged gel electrophoresis using 1.5\% agarose gels with DNA size markers (Promega PCR markers), and obtained DNA fragments were visualized by ethidium bromide staining before sequencing. PCR products were sequenced in both directions directly, using the wsp 81F and wsp 691R primers used for DNA amplification. The sequences were then edited using Staden package software and compared to homologous sequences in GenBank thanks to the nucleotide Basic Local Alignment Search Tool (BLAST: www.ncbi.nlm.nih.gov/BLAST) in order to identify the samples at the species level. Strains were considered as identified at the species level when their sequence showed $\geq 99 \%$ homology with a sequence deposited in GenBank. Sequences were also aligned with BioEdit v7.0.0 software [12] for comparison.

\section{Results}

In the present study, the prospected samples were demonstrated to have suitable DNA quality using Nanodrop spectrometry and electrophoresis gel running. In total, 


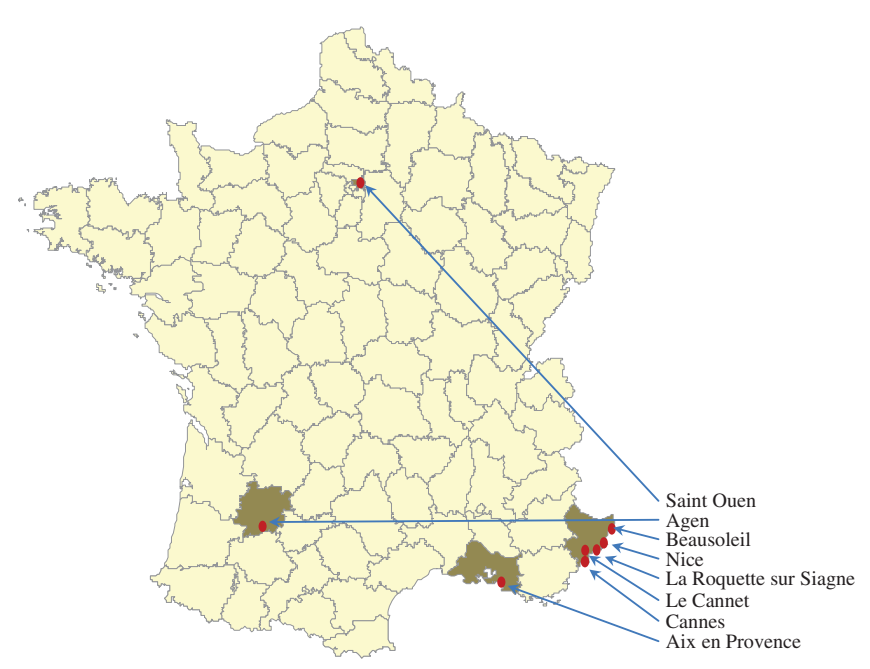

Figure 1. Collect sites of bed bug (C. lectularius) populations in France.

284 bed bug specimens were captured from eight sites: Aixen-Provence, Saint-Ouen, Nice, Beausoleil, Le Cannet, Cannes, La Roquette-sur-Siagne, and Agen. They were screened to detect the Wolbachia wsp gene. The largest number of samples was from Nice (96 samples) followed by Aixen-Provence (89 samples), and the lowest number of samples analyzed in this study was from La Roquette-sur-Siagne (4 samples). Among all samples, 166 were adults and the remaining samples (117) were considered nymphs (Fig. 2, Table 1).

Based on the results, 47 out of 118 nymphs (40.2\%) and 61 out of 166 adults $(36.7 \%)$ were found positive in wsp PCR screening (Fig. 2, Table 1). Among positive samples, PCR products of 10 samples were selected randomly to perform sequencing. These samples carried Wolbachia DNA according to the BLAST process. The sequences obtained from this study have been deposited in GenBank under Accession Numbers KR706518 to KR706527. They are identical or highly similar (100\% homology) to several Wolbachia sequences from C. lectularius deposited in GenBank, including isolates from Australia (AB475130, AB475131), Japan (AB475128, AB475129), and USA (DQ842459).

\section{Discussion}

In recent years, several investigations have concentrated on Wolbachia infection among different arthropod hosts. These studies are important for several reasons: (i) Wolbachia species are important for studies targeting evolutionary processes due to their widespread distribution among different host populations, (ii) Wolbachia species can be used in studies focusing on biological and cellular processes because they lead to changes in the development and mitotic processes in their hosts, and (iii) due to the potential role of Wolbachia species in reducing host ability to reproduce and consequently decreasing the population size, they are an important part of biological control of vector/pest insect populations [2, 7, 17]. These reasons have thus encouraged researchers to investigate the occurrence and prevalence of Wolbachia in several different insects, including bed bugs.

For this purpose, studies conducted to survey Wolbachia infection among bed bug populations have used samples from nature as well as from laboratories. Rasgon and Scott [25] identified Wolbachia symbionts in laboratory colonized cliff swallow bugs (Oeciacus vicarious Horvath) and common bed bugs (Cimex lectularius) by PCR amplification and sequencing using Wolbachia-specific 16S rDNA and FtsZ genes. Their phylogenetic analyses indicated that Wolbachia infections in these two cimicid hosts form a monophyletic group, and the Wolbachia strains detected belong to the F clade. In the same way, Baldo et al. [1] carried out a multilocus sequence typing (MLST) study on 42 laboratory-reared bed bug specimens harboring single infection with different Wolbachia pipientis strains, using a specific set of markers, e.g. wsp, FtsZ, and $16 \mathrm{~S}$. Their results demonstrated that the Wolbachia strains isolated from their prospected Cimex lectularius belonged to the $\mathrm{F}$ supergroup. Four years later, Hosokawa et al. [14] characterized the bacterial symbionts of laboratory bed bug samples including two Japanese (TUA and $\mathrm{TIH}$ ) and two Australian samples (SYDW and SYDL). They isolated Wolbachia species from each bed bug specimen individually and conducted PCR, cloning, and sequencing of a bacterial 16S rRNA gene fragment. They reported complete similarity for Wolbachia strains isolated from Japanese and Australian bed bugs.

All of the mentioned studies were carried out on bed bug samples from laboratory colonies. Endosymbiotic Wolbachia bacteria have previously been shown to infect laboratory colonies of the common bed bug, Cimex lectularius, but there is little information on the extent of infection in natural populations. One of the studies on the prevalence of Wolbachia infection among field collected samples was carried out by Sakamoto and Rasgon [29] on 39 bed bug samples from the United States and Zambia. They concluded that Wolbachia infections were prevalent in the populations with an infection rate of $83 \%-100 \%$ and there were no significant differences in infection frequency between geographic regions, between sexes, or between life stages (adult versus nymph). Recently, Siddiqui and Raja [33] assayed Cimex lectularius populations from different regions of India for Wolbachia infection using a PCR-based analysis. They reported an infection rate of over $75 \%$ for their prospected samples.

To our knowledge, the present study is the first epidemiological investigation carried out in France, as well as Europe, on field collected bed bugs in order to detect and identify Wolbachia strains and prevalence among samples that come from different regions of France.

The total rate of Wolbachia infection of bed bugs in this study is calculated as $38.2 \%$ which is lower than rates reported by Sakamoto and Rasgon [30] and by Siddiqui and Raja [33]. This value is, however, an underestimate compared to infection rates reported previously for $C$. lectularius. To date, no study has been conducted on Wolbachia infection in C. lectularius in France. However, analysis with more bed bug samples in terms of quantity and diversity from different biological (male/female, nymph/adult) and physiological (unfed/blood fed, parous/nulliparous) stages will enhance 


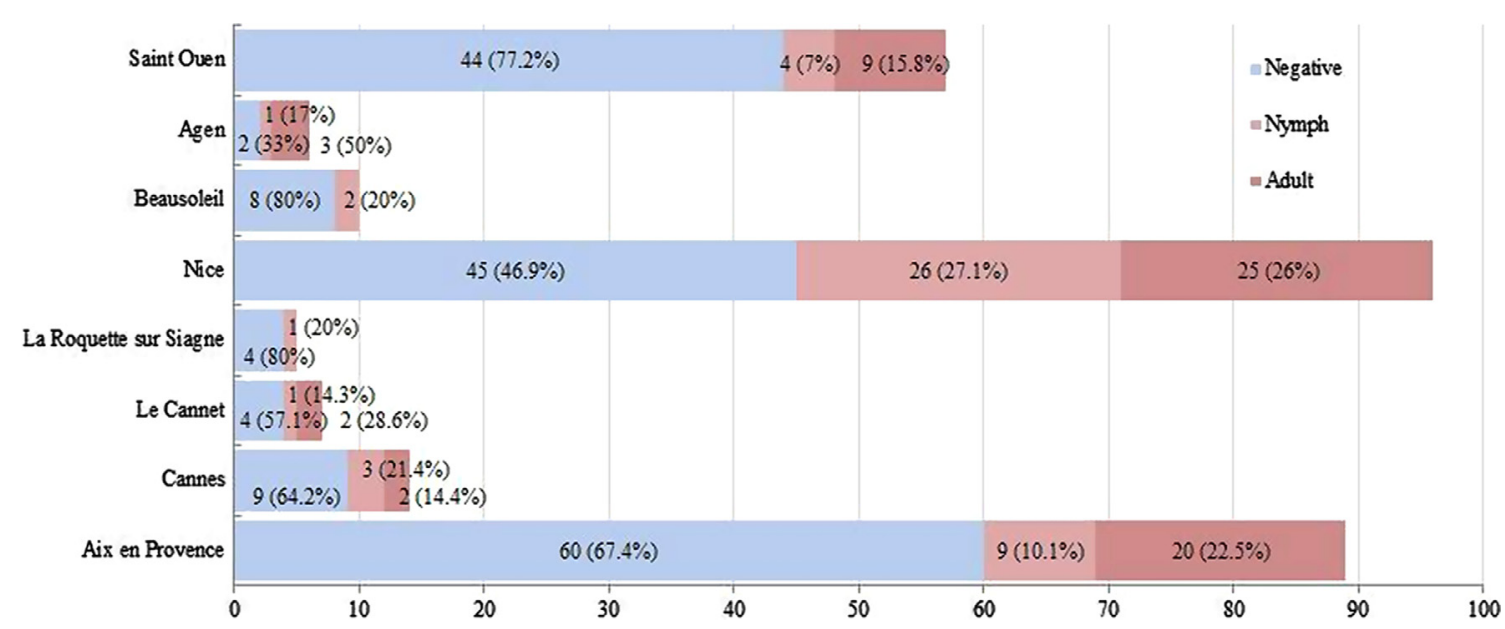

Figure 2. Number (percent) positivity for Wolbachia in adult and nymph bed bugs in different regions.

Table 1. Cimex lectularius populations prospected for Wolbachia infection in the present study.

\begin{tabular}{|c|c|c|c|c|c|c|c|c|c|}
\hline \multirow{2}{*}{$\begin{array}{l}\text { District } \\
\text { City }\end{array}$} & \multirow{2}{*}{$\begin{array}{c}\text { Bouches-du- } \\
\text { Rhône } \\
\text { Aix-en- } \\
\text { Provence }\end{array}$} & \multirow{2}{*}{$\begin{array}{c}\text { Suburbs of } \\
\text { Paris } \\
\text { Saint-Ouen }\end{array}$} & \multicolumn{5}{|c|}{ Alpes-Maritimes } & \multirow{2}{*}{$\begin{array}{c}\begin{array}{c}\text { Lot-et- } \\
\text { Garonne }\end{array} \\
\text { Agen }\end{array}$} & \multirow{2}{*}{ Total } \\
\hline & & & Nice & Beausoleil & Le Cannet & Cannes & $\begin{array}{l}\text { La Roquette- } \\
\text { sur-Siagne }\end{array}$ & & \\
\hline C. lecturius & Nymph Adult & Nymph Adult & Nymph Adult & Nymph Adult & lymph Adul & Nymph Adult & Nymph Adult & Nymph Adult & \\
\hline$\overline{W s p+/ \text { Samples }}$ & $\begin{array}{ll}9 / 31 & 20 / 58\end{array}$ & $4 / 19 \quad 9 / 38$ & $26 / 50 \quad 25 / 46$ & $2 / 4 \quad 0 / 6$ & $1 / 2$ & $2 / 5$ & $0 / 4$ & $3 / 4$ & $\overline{108 / 284}$ \\
\hline Total & $29 / 89$ & $13 / 57$ & $51 / 96$ & $2 / 10$ & $3 / 7$ & $5 / 14$ & $1 / 5$ & $4 / 6$ & $38.1 \%$ \\
\hline
\end{tabular}

findings and provide a more accurate estimate of the Wolbachia infection rate in C. lectularius in France. Also, among positive cases, 10 samples were selected and sequenced randomly. The obtained sequences were edited, aligned, and blasted with GenBank database sequences to identify Wolbachia species. These sequences were identified as Wolbachia sp. and had 100\% and 99\% homology with other already known wsp sequences reported from Cimex lectularius (DQ842459 from the United States) and Cimex japonicas (AB508952 from Japan), respectively, which belong to the $\mathrm{F}$ supergroup strains of the Wolbachia genus. These sequences also had more than 95\% homology with Wolbachia pipientis bacterium as a type strain of the Wolbachia genus, demonstrating the genetic variations and subdivision of the Wolbachia genus.

\section{Conclusion}

This is the first epidemiological study of this kind carried out in France as well as Europe. This study allowed us to identify the prevalence of Wolbachia infection among several bed bug populations collected from different localities and to compare our findings with previously reported results in the literature. Our results demonstrate the occurrence of Wolbachia infection in both nymphs and adults of C. lectularius, although the infection rates were not similar. Based on sequencing results obtained from partial DNA amplification of the wsp gene, there was $100 \%$ homology with
Wolbachia wsp sequences (previously associated with C. lectularius), reported from other regions, such as the United States and Japan.

\section{Competing interests}

The authors declare that they have no competing interests.

Acknowledgements. This work was supported by the "Projet Hospitalier de Recherche Clinique 2009" of the French Ministry of Health. We thank Dr Emmanuel Lemichez, Director of team 6 Inserm U1065, Centre Méditerranéen de Médecine Moléculaire.

\section{References}

1. Baldo L, Dunning Hotopp JC, Jolley KA, Bordenstein SR, Biber SA, Choudhury RR, Hayashi C, Maiden MCJ, Tettelin H, Werren JH. 2006. Multilocus sequence typing system for the endosymbiont Wolbachia pipientis. Applied and Environmental Microbiology, 72, 7098-7110.

2. Beard CB, O'Neill SL, Tesh RB, Richard FF, Aksoy S. 1993. Modification of arthropod vector competence via symbiotic bacteria. Parasitology Today, 9, 179-183.

3. Bordenstein S, Rosengaus RB. 2005. Discovery of a novel Wolbachia supergroup in Isoptera. Current Microbiology, 51, 393-398.

4. Bourtzis K, Miller TA. 2006. Insect symbiosis, Volume 3, Bourtzis K, Miller TA, Editors. CRC Press: Boca Raton, Florida. p. 424. 
5. Brownlie JC, Johnson KN. 2009. Symbiont-mediated protection in insect hosts. Trends in Microbiology, 17, 348-354.

6. Chrostek E, Marialva MSP, Yamada R, O’Neill SL, Teixeira L. 2014. High anti-viral protection without immune upregulation after interspecies Wolbachia transfer. PLoS One, 9, e99025.

7. Cook PE, McGraw EA. 2010. Wolbachia pipientis: an expanding bag of tricks to explore for disease control. Trends in Parasitology, 26, 373-375.

8. Cordaux R, Bouchon D, Gréve P. 2011. The impact of endosymbionts on the evolution of host sex-determination mechanisms. Trends in Genetics, 27, 332-341.

9. Douglas AE. 1998. Nutritional interactions in insect-microbial symbioses: aphids and their symbiotic bacteria Buchnera. Annual Review of Entomology, 43, 17-37.

10. Engelstadter J, Hurst GDD. 2009. The ecology and evolution of microbes that manipulate host reproduction. Annual Review of Ecology, Evolution, and Systematics, 40, 127-149.

11. Guruprasad NM, Jalali SK, Puttaraju HP. 2014. Wolbachia - a foe for mosquitoes. Asian Pacific Journal of Tropical Diseases, $4,78-81$

12. Hall TA. 1999. Bioedit: a user-friendly biological sequence alignment editor and analysis program for Windows 95/98/NT. Nucleic Acids Symposium Series, 41, 95-98.

13. Heaton LL. 2013. Wolbachia in bed bugs Cimex lectularius. PhD Thesis, University of Sheffield.

14. Hosokawa T, Koga R, Kikuchi Y, Meng XY, Fukatsu T. 2010. Wolbachia as a bacteriocyte-associated nutritional mutualist. Proceedings of the National Academy of Sciences USA, 107, 769-774.

15. Leulmi H, Bitam I, Berenger JM, Lepidi H, Rolain JM, Almeras L, Raoult D, Parola P. 2015. Competence of Cimex lectularius bed bugs for the transmission of Bartonella quintana, the agent of trench fever. PLoS Neglected Tropical Diseases, 9, e0003789.

16. Martinez J, Longdon B, Bauer S, Chan YS, Miller WJ, Bourtzis K, Teixeira L, Jiggins FM. 2014. Symbionts commonly provide broad spectrum resistance to viruses in insects: a comparative analysis of Wolbachia strains. PLoS Pathogens, 10, e1004369.

17. McGraw EA, O'Neill SL. 2013. Beyond insecticides: new thinking on an ancient problem. Nature Reviews Microbiology, 11, 181-193.

18. Meriweather M, Matthews S, Rio R, Baucom RS. 2013. A 454 survey reveals the community composition and core microbiome of the common bed bug (Cimex lectularius) across an urban landscape. PLoS One, 8, e61465.

19. Moran NA, Telang A. 1998. Bacteriocyte-associated symbionts of insects. BioScience, 48, 295-304.

20. Moriyma M. 2012. Comparative transcriptomics of the bacteriome and the spermalege of the bed bug Cimex lectularius (Hemiptera: Cimicidae). Applied Entomology and Zoology, 47, 233-243.

21. Nikoh N, Hosokawa T, Moriyama M, Oshima K, Hattori M, Fukatsu T. 2014. Evolutionary origin of insect-Wolbachia nutritional mutualism. Proceedings of the National Academy of Sciences USA, 111, 10257-10262.
22. Nogge G. 1981. Significance of symbionts for the maintenance of an optimal nutritional state for successful reproduction in haematophagous arthropods. Parasitology, 82, 101-104.

23. O'Neill SL, Giordano R, Colbert AM, Karr TL, Robertson HM. 1992. 16S rRNA phylogenetic analysis of the bacterial endosymbionts associated with cytoplasmic incompatibility in insects. Proceedings of the National Academy of Sciences USA, 89, 2699-2702.

24. O'Neill SL, Hoffmann AA, Werren JH. 1997. Influential passengers: inherited microorganisms and arthropod reproduction. Oxford University Press: New York, NY.

25. Rasgon JL, Scott TW. 2004. Phylogenetic characterization of Wolbachia symbionts infecting Cimex lectularius L. and Oeciacus vicarius Horvath (Hemiptera: Cimicidae). Journal of Medical Entomology, 41, 1175-1178.

26. Rousset F, Bouchon D, Pintureau B, Juchault P, Solignac M. 1992. Wolbachia endosymbionts responsible for various alterations of sexuality in arthropods. Proceedings of the Royal Society of London Series B, Biological Sciences, 250, 91-98.

27. Rowley SM, Raven RJ, McGraw EA. 2004. Wolbachia pipientis in Australian spiders. Current Microbiology, 49, 208-214.

28. Saenz VL, Maggi RG, Breitschwerdt EB, Kim J, Vargo EL, Schal C. 2013. Survey of Bartonella spp. in US bed bugs detects Burkholderia multivorans but not Bartonella. PLoS One, 8, e73661.

29. Sakamoto JM, Rasgon JL. 2006. Geographic Distribution of Wolbachia Infections in Cimex lectularius (Heteroptera: Cimicidae). Journal of Medical Entomology, 43, 696-700.

30. Sakamoto JM, Rasgon JL. 2006. Endosymbiotic bacteria of bed bugs: evolution, ecology and genetics. American Entomologist, $52,11-122$.

31. Sakamoto JM, Feinstein J, Rasgon JL. 2006. Wolbachia infections in the Cimicidae: museum specimens as an untapped resource for endosymbiont surveys. Applied and Environment Microbiology, 72, 3161

32. Salazar R, Castillo-Neyra R, Tustin AW, Borrini-Mayori K, Náquira C, Levy MZ. 2015. Bed bugs (Cimex lectularius) as Vector of Trypanosoma cruzi. American Journal of Tropical Medicine and Hygiene, 92, 331-335.

33. Siddiqui SS, Raja IA. 2015. Molecular detection of endosymbiont bacteria Wolbachia in bed bug species Cimex lectularius from Vidarbha region of India. International Journal of Life Sciences, 3, 200-204.

34. Stouthamer R, Hu JG, Van Kan FJPM, Platner GR, Pinto JD. 1999. The utility of internally transcribed spacer 2 DNA sequences of the nuclear ribosomal gene for distinguishing sibling species of Trichogramma. Biocontrol, 43, 421-440.

35. Werren JH, O'Neill SL. 1997. The Evolution of Heritable Symbionts. Oxford University Press: Oxford. p. 1-41.

36. Zhou W, Rousset F, O'Neill S. 1998. Phylogeny and PCR-based classification of Wolbachia strains using wsp gene sequences. Proceedings of the Royal Society of London, Series B, Biological Sciences, 265, 509-515.

37. Zug R, Hammerstein P. 2015. Bad guys turned nice? A critical assessment of Wolbachia mutualisms in arthropod hosts. Biological reviews of the Cambridge Philosophical Society, 90, 89-111. 
Cite this article as: Akhoundi M, Cannet A, Loubatier C, Berenger J-M, Izri A, Marty P \& Delaunay P: Molecular characterization of Wolbachia infection in bed bugs (Cimex lectularius) collected from several localities in France. Parasite, 2016, 23, 31.

0 PARASTE

An international open-access, peer-reviewed, online journal publishing high quality papers on all aspects of human and animal parasitology

Reviews, articles and short notes may be submitted. Fields include, but are not limited to: general, medical and veterinary parasitology; morphology, including ultrastructure; parasite systematics, including entomology, acarology, helminthology and protistology, and molecular analyses; molecular biology and biochemistry; immunology of parasitic diseases; host-parasite relationships; ecology and life history of parasites; epidemiology; therapeutics; new diagnostic tools.

All papers in Parasite are published in English. Manuscripts should have a broad interest and must not have been published or submitted elsewhere. No limit is imposed on the length of manuscripts.

Parasite (open-access) continues Parasite (print and online editions, 1994-2012) and Annales de Parasitologie Humaine et Comparée (1923-1993) and is the official journal of the Société Française de Parasitologie. 